\title{
Predictors of Depressive Mood in Patients With Isolated Cerebellar Stroke: A Retrospective Study
}

\author{
Dong Jin Koh, MD, Na Young Kim, MD, Yong Wook Kim, MD, PhD
}

Department of Rehabilitation Medicine and Research Institute of Rehabilitation Medicine, Yonsei University College of Medicine \& Severance Hospital, Seoul, Korea

Objective To identify predictive factors of depressive mood in patients with isolated cerebellar stroke.

Methods A retrospective chart review was performed in patients who had experienced their first isolated cerebellar stroke during 2002-2014. The patients were classified into two groups by the Geriatric Depression Scale (GDS) (non-depressive group, $0 \leq \mathrm{GDS} \leq 16$; depressive group, $17 \leq \mathrm{GDS} \leq 30$ ). Data on demographic and socioeconomic factors, comorbidities, functional level, cognitive and linguistic function, and stroke characteristics were collected. Significant variables in univariate analysis were analyzed using logistic regression.

Results Fifty-two patients were enrolled, of whom $55.8 \%$ had depressive mood, were older $(\mathrm{p}=0.021)$, and had higher hypertension rates $(\mathrm{p}=0.014)$. Cognitive and linguistic functions did not differ between the two groups. The depressive group had higher ischemic stroke rates $(\mathrm{p}=0.035)$ and showed a dominant right posterior cerebellar hemisphere lesion $(\mathrm{p}=0.028)$, which was independently associated with depressive mood in the multiple logistic regression analysis (odds ratio, 5.081; 95\% confidence interval, 1.261-20.479).

Conclusion The risk of depressive mood after cerebellar stroke was increased in patients at old age, with a history of hypertension, ischemic stroke, and lesion of the right posterior cerebellar hemisphere. The most significant determining factor was stroke lesion of the right posterior cerebellar hemisphere. Early detection of risk factors is important to prevent and manage depressive mood after cerebellar stroke.

Keywords Cerebellum, Stroke, Depression, Risk factors

\section{INTRODUCTION}

Post-stroke depressive mood (PSDM) is a serious and common complication that occurs in one-third of the total number of stroke patients [1]. As PSDM has been found to significantly affect functional outcome, resump-

Received August 20, 2015; Accepted September 25, 2015

Corresponding author: Yong Wook Kim

Department of Rehabilitation Medicine and Research Institute of Rehabilitation Medicine, Yonsei University College of Medicine \& Severance Hospital, 50-1 Yonsei-ro, Seodaemun-gu, Seoul 03722, Korea. Tel: +82-2-2228-3716, Fax: +82-2-363-2795, E-mail: ywkim1@yuhs.ac

ORCID: Dong Jin Koh (http://orcid.org/0000-0001-5673-3068); Na Young Kim (http://orcid.org/0000-0001-9888-3953); Yong Wook Kim (http://orcid. org/0000-0002-5234-2454).

(c) This is an open-access article distributed under the terms of the Creative Commons Attribution Non-Commercial License (http://creativecommons.org/ licenses/by-nc/4.0) which permits unrestricted noncommercial use, distribution, and reproduction in any medium, provided the original work is properly cited. Copyright $\odot 2016$ by Korean Academy of Rehabilitation Medicine 
tion of social activities, and quality of life [2], numerous studies have been conducted to evaluate and manage PSDM in patients in the early phase of stroke [3-8]. Although the studies showed inconsistent results, factors such as sex, stroke severity, functional impairments, family, and social support were the most frequently mentioned risk factors [9]. However, most of the studies included patients who had a supratentorial stroke.

Recent bodies of evidence from studies have revealed that the cerebellum might play an important role in the regulation of emotion $[10,11]$. The study by Shah et al. [12] showed that patients with a major depressive disorder have reduced cerebellar volume. Leroi et al. [13] found that patients with cerebellar degeneration had high prevalence of depressive mood. In cerebellar stroke patients, Frank et al. [14] observed significantly high depression scores. However, there are a few studies on PSDM after isolated cerebellar stroke.

Therefore, the aim of this study was to analyze the association between the clinical data of isolated cerebellar stroke patients and the occurrence of depressive mood in order to identify predictive factors of depressive mood after isolated cerebellar stroke and help early detection.

\section{MATERIALS AND METHODS}

\section{Subjects}

Data were collected retrospectively from the medical records of the patients, who were diagnosed as having cerebellar stroke and hospitalized in the Department of Rehabilitation Medicine at Severance Hospital from January 2002 to December 2014.

The inclusion criteria were (1) patients with isolated cerebellar stroke confirmed by a neuroimaging study (brain computed tomography [CT] or magnetic resonance imaging $[\mathrm{MRI}]$ ) and neurological examination, (2) patients who experienced their first stroke, and (3) patients older than 18 years. The exclusion criteria were (1) patients with disorders of consciousness (vegetative state or minimally conscious state), (2) patients with severe cognitive deficit with Korean Mini-Mental State Examination (K-MMSE) scores $<10$ points, and (3) patients with a history of psychiatric or neurological disorders diagnosed before their stroke.

\section{Demographic and socioeconomic characteristics}

The clinical data of the subjects, including their demographic characteristics such as age and sex, and socioeconomic characteristics such as employment status, family status, religion, urbanicity, and education level, were collected from their medical records.

\section{Comorbidities}

Data on the medical histories and comorbidities such as hypertension, diabetes mellitus, smoking and alcohol consumption, cardiovascular disease, and orthopedic disease of the subjects were collected from their medical records. Data on other medical comorbidities such as pulmonary and kidney diseases were also collected.

Linguistic function, cognitive function, and functional status

The results of the Korean version of the Western Aphasia Battery (K-WAB) and Boston Naming Test (BNT) were used for evaluation of linguistic function [15]. To measure the cognitive function of each patient, the results of the K-MMSE were used.

The Functional Independence Measure (FIM) is a functional tool to assess activities of daily living, with a total score of 126 points, and 13 items that define motor function disability (FIM-motor) and 5 items that define cognitive function disability (FIM-cog) [16]. We analyzed the correlation of each domain with depressive mood.

\section{Type of stroke and localization of lesion}

The brain MRI and CT results of all the recruited patients were reviewed by a radiologist who had more than 3 years of clinical experience. The type of stroke lesion (ischemic or hemorrhagic lesion) was recorded. The lesion locations of cerebellar stroke were classified into the following five categories: right anterior, right posterior, left anterior, and left posterior lobes, and vermian lesion in the middle sagittal view.

\section{Evaluation of depressive mood}

Depressive mood was evaluated according to the Geriatric Depression Scale (GDS) score [17]. This scale consists of 30 yes-or-no questions, with 1 point scored for yes and 0 points scored for no, for a total of 30 points. Scores $>17$ points have been reported to indicate a high possibility of major depressive disorder [18]. The patients were 
classified into two groups according to a cutoff score of 16 in order to identify the correlation between depressive mood and clinical factors (non-depressive group, $0 \leq \mathrm{GDS} \leq 16$; depressive group, $17 \leq \mathrm{GDS} \leq 30$ ).

\section{Statistical analyses}

SPSS ver. 22.0 (IBM SPSS Inc., Armonk, NY, USA) was used for statistical analyses. The association between depressive mood and categorical variables, including sex, employment status, family status, religion, urbanicity, education level, various comorbidities, dysarthria, type of stroke lesion, and lesion location of cerebellar stroke, was assessed by using the $\chi^{2}$ test and Fisher exact test. The Mann-Whitney U test was used for continuous variables such as age, K-MMSE, BNT, aphasia quotient, language quotient, and FIM score. In order to identify the risk factors for depressive mood, a binary logistic regression model was used. Statistical significance was determined at $\mathrm{p}<0.05$.

\section{RESULTS}

Among all the patients, 137 had cerebellar stroke, of whom 52 satisfied both the inclusion and exclusion criteria, as shown in Fig. 1. We classified 23 subjects into the non-depressive group and 29 subjects into the depressive group (Fig. 1).

Depressive mood in relation to demographic and socioeconomic factors, and comorbidities

With respect to demographic factors, socioeconomic factors, and comorbidities, age $(\mathrm{p}=0.021)$ and history of hypertension $(\mathrm{p}=0.014)$ showed statistically significant correlations with depressive mood (Table 1). Other factors such as sex, employment status, family status, religion, urbanicity, and education level did not show significant correlations with depressive mood. In addition, comorbidities such as diabetes mellitus, history of smoking and alcohol consumption, cardiovascular disease, orthopedic disease, and other medical diseases did not show a significant correlation with depressive mood. A trend was observed among unmarried subjects with

Exclusion criteria $(n=10)$

(1) Disorders of consciousness $(n=3)$

(2) Severe cognitive deficit $(n=3)$

(3) Any history of psychiatric and neurologica disorders diagnosed before $(n=4)$

Failed to meet the inclusion criteria $(n=75)$

(1) Not isolated cerebellar stroke $(n=60)$

(2) Not the first stroke $(n=13)$

(3) Age younger than 18 years $(n=2)$

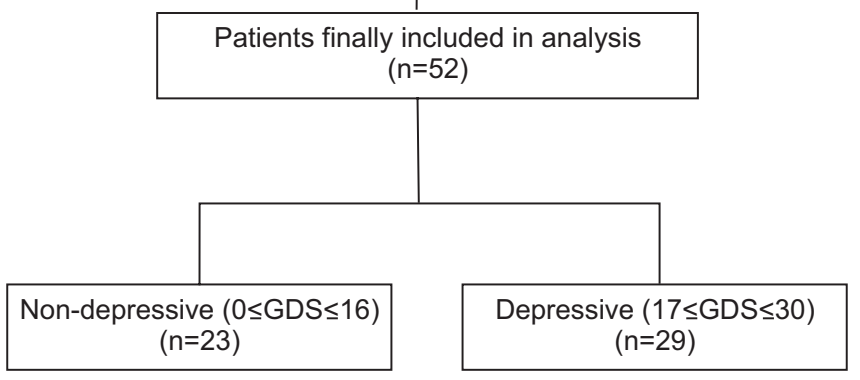

Fig. 1. Flowchart of the subjects. A total of 137 patients with cerebellar stroke were assessed from January 1, 2002 to December 31, 2014. Finally, 52 patients were included and they were classified into two groups according to the Geriatric Depression Scale (GDS). 
Table 1. Demographic factors, socioeconomic factors, and comorbidities of depressive and non-depressive patients after isolated cerebellar stroke

\begin{tabular}{|c|c|c|c|}
\hline Variable & Non-depressive group $(\mathrm{n}=\mathbf{2 3})$ & Depressive group $(\mathrm{n}=29)$ & p-value \\
\hline Age (yr) & $47.7 \pm 19.8$ & $60.5 \pm 15.0$ & $0.02^{*}$ \\
\hline \multicolumn{4}{|l|}{ Sex } \\
\hline Male & $11(47.8)$ & $8(27.6)$ & 0.13 \\
\hline Female & $12(52.2)$ & $21(72.4)$ & \\
\hline Duration after onset (day) & $117.2 \pm 188.2$ & $133.8 \pm 166.2$ & 0.22 \\
\hline \multicolumn{4}{|l|}{ Employment status } \\
\hline Unemployed & $4(17.4)$ & $11(37.9)$ & 0.10 \\
\hline Employed & $19(82.6)$ & $18(62.1)$ & \\
\hline \multicolumn{4}{|l|}{ Family status } \\
\hline Unmarried & $7(30.4)$ & $3(10.3)$ & 0.08 \\
\hline Married & $16(69.6)$ & $26(89.7)$ & \\
\hline \multicolumn{4}{|l|}{ Religion } \\
\hline No & $11(47.8)$ & $13(44.8)$ & 0.82 \\
\hline Yes & $12(52.2)$ & $16(55.2)$ & \\
\hline \multicolumn{4}{|l|}{ Urbanicity } \\
\hline Rural & $4(17.4)$ & $3(10.3)$ & 0.68 \\
\hline Urban & $19(82.6)$ & $26(89.7)$ & \\
\hline \multicolumn{4}{|l|}{ Education (yr) } \\
\hline$<6$ & $4(17.4)$ & $4(13.8)$ & 0.22 \\
\hline$>6$ and $<12$ & $8(34.8)$ & $17(58.6)$ & \\
\hline$>12$ & $11(47.8)$ & $8(27.6)$ & \\
\hline \multicolumn{4}{|l|}{ Comorbidities } \\
\hline Hypertension & $8(34.8)$ & $20(69.0)$ & $0.01^{*}$ \\
\hline Diabetes mellitus & $4(17.4)$ & $10(34.5)$ & 0.16 \\
\hline Smoking & $7(30.4)$ & $14(48.3)$ & 0.19 \\
\hline Alcohol & $9(39.1)$ & $18(62.1)$ & 0.10 \\
\hline Cardiovascular disease & $5(21.7)$ & $4(13.8)$ & 0.45 \\
\hline Pulmonary disease & $4(17.3)$ & $10(34.5)$ & 0.16 \\
\hline Renal disease & $3(13.0)$ & $4(13.8)$ & 1.00 \\
\hline Orthopedic disease & $3(13.0)$ & $4(13.8)$ & 1.00 \\
\hline
\end{tabular}

Values are presented as mean \pm standard deviation or number (\%).

${ }^{*} \mathrm{p}<0.05$.

depressive mood, although no statistically significant difference was observed between the depressive and nondepressive groups.

Depressive mood in relation to linguistic function, cognitive function, and functional level

Lower aphasia quotient $(\mathrm{p}=0.075)$ showed a trend of relative association with depressive mood, although the association was not statistically significant. With respect to the subjects' functional level, the FIM scores in the total, motor, and cognitive domains did not show statistically significant differences between the two groups (Table 2).

Depressive mood in relation to type of stroke and localization of lesion

Among the lesion variables, the stroke location of right posterior cerebellar hemisphere $(\mathrm{p}=0.028)$ and ischemic cerebellar stroke showed statistically significant associations with depressive mood (Table 3). Other lesional 
Table 2. Linguistic function, cognitive function, and functional status of depressive and non-depressive patients after isolated cerebellar stroke

\begin{tabular}{|c|c|c|c|}
\hline Variable & Non-depressive group $(n=23)$ & Depressive group $(\mathrm{n}=29)$ & p-value \\
\hline \multicolumn{4}{|l|}{ Linguistic function } \\
\hline \multicolumn{4}{|l|}{ K-WAB } \\
\hline Dysarthria & $8(34.8)$ & $12(41.4)$ & 0.22 \\
\hline Aphasia quotient & $90.0 \pm 8.9$ & $82.8 \pm 14.3$ & 0.07 \\
\hline Language quotient & $90.6 \pm 7.9$ & $85.4 \pm 13.0$ & 0.32 \\
\hline BNT & $45.0 \pm 13.9$ & $41.5 \pm 11.5$ & 0.19 \\
\hline \multicolumn{4}{|l|}{ Cognitive function } \\
\hline K-MMSE & $25.1 \pm 4.0$ & $23.3 \pm 4.8$ & 0.15 \\
\hline \multicolumn{4}{|l|}{ FIM score } \\
\hline FIM-total & $72.7 \pm 26.9$ & $63.7 \pm 26.8$ & 0.19 \\
\hline FIM-motor & $45.4 \pm 20.9$ & $39.0 \pm 20.1$ & 0.29 \\
\hline FIM-cognition & $27.3 \pm 8.5$ & $24.8 \pm 9.0$ & 0.23 \\
\hline
\end{tabular}

Values are presented as number (\%) or mean \pm standard deviation.

K-WAB, Korean version of the Western Aphasia Battery; BNT, Boston Naming Test; K-MMSE,Korean Mini-Mental State Examination; FIM, Functional Independence Measure.

${ }^{*} \mathrm{p}<0.05$.

Table 3. Type of stroke and lesion localization in depressive and non-depressive patients after isolated cerebellar stroke

\begin{tabular}{|cccc}
\hline \multicolumn{1}{c}{ Variable } & Non-depressive group $(\mathbf{n = 2 3 )}$ & Depressive group $(\mathbf{n}=\mathbf{2 9})$ & p-value \\
\hline Type of stroke lesion & & & \\
\hline Ischemic & $10(43.5)$ & $21(72.4)$ & $0.03^{*}$ \\
\hline Hemorrhage & $13(56.5)$ & $8(27.6)$ & \\
\hline Cerebellar lesion & & & 0.25 \\
\hline Right, anterior & $6(26.1)$ & $12(41.4)$ & $0.02^{*}$ \\
\hline Right, posterior & $8(34.8)$ & $19(65.5)$ & 0.57 \\
\hline Left, anterior & $8(34.8)$ & $8(27.6)$ & 0.75 \\
\hline Left, posterior & $16(69.6)$ & $19(65.5)$ & 0.59 \\
\hline Vermis & $12(52.2)$ & $13(44.8)$ & \\
\hline
\end{tabular}

Values are presented as number (\%).

${ }^{*} \mathrm{p}<0.05$.

factors showed no statistically significant differences between the two groups.

Risk factors for depressive mood in isolated cerebellar stroke in the logistic regression analysis

Table 4 describes the results of the multifactorial binary logistic regression analysis on the risk factors that could affect depressive mood. The factors, including lesion pathology, history of hypertension, and age, were identified as statistically non-significant risk factors. Only stroke in the right posterior cerebellar hemisphere was identified
Table 4. Results of the multifactorial binary logistic regression analysis on risk factors for depressive mood in patients with isolated cerebellar stroke

\begin{tabular}{lccc}
\hline \multicolumn{1}{c}{ Variable } & OR & \multicolumn{1}{c}{$\mathbf{9 5 \%}$ CI } & p-value \\
\hline Right, posterior lesion & 5.081 & $1.261-20.479$ & $0.02^{*}$ \\
Age & 1.028 & $0.985-1.074$ & 0.20 \\
$\begin{array}{l}\text { Ischemic } \\
\text { cerebellar stroke }\end{array}$ & 0.358 & $0.084-1.522$ & 0.16 \\
$\begin{array}{l}\text { History of } \\
\text { hypertension }\end{array}$ & 2.004 & $0.449-8.946$ & 0.36 \\
\hline
\end{tabular}

OR, odds ratio; CI, confidence interval.

${ }^{*} \mathrm{p}<0.05$. 
as a risk factor (odds ratio, 5.081; 95\% confidence interval, 1.261-20.479), considering the effects of the other factors.

\section{DISCUSSION}

In this study, older age, history of hypertension, ischemic lesion rather than hemorrhagic lesion, and lesion of the right posterior cerebellar hemisphere were correlated with depressive mood in isolated cerebellar stroke patients. When the effects of the other factors were assessed, lesion of the right posterior cerebellar hemisphere was the only factor that correlated with depressive mood.

Previous research studies identified female sex [19], severe functional impairment $[20,21]$, previous history of depression [22], aphasia [23], and absence of family and social support as the risk factors for PSDM [24]. However, our study did not show a relationship between these factors and depressive mood after cerebellar stroke. As the subjects of our study were limited to those with isolated cerebellar stroke, it may be difficult to apply the risk factors reported in previous studies.

In this study, older patients were more depressed than younger patients. In a normal population, the aging process itself increases the risk of depressive mood [25]. In stroke patients, the tendency for developing depressive mood after stroke is more frequently observed at an older age [26]. The atherosclerotic, inflammatory, endocrinologic and immunologic changes related to the aging process might form the pathophysiological mechanism that is responsible for increasing the vulnerability to depression [27].

The risk of depressive mood was higher in the patients who had a history of hypertension. Previous history of hypertension could cause the change of periventricular white matter hyperintensity [28], which is one of the risk factors for depressive mood in the elderly [29]. Due to this reason, the comorbid condition of previous hypertension can increase the risk of depressive mood in patients with isolated cerebellar stroke, although we did not measure the lesion of periventricular white matter change. Regarding another probable explanation, a study conducted by Meurs et al. [30] demonstrated that the patients with the combination of major depressive disorder and hypertension showed decreases of brain volumes in the areas associated with emotional regulation, such as anterior and middle cingulate cortices and cerebellum. The alterations of brain volume in these emotional regulatory areas might be an explanation for the comorbidity between hypertension and depressive mood. Further studies should be performed to confirm our results.

The patients with ischemic cerebellar stroke were more vulnerable to depressive mood than those with hemorrhagic stroke; however, previous studies showed controversial results $[20,24,31]$. The present study showed that ischemic stroke was bivariately related to depressive mood, but it failed to demonstrate the relationship in a multivariate logistic regression model. Similar results were observed in a study conducted by van de Port et al. [31]. In this study, ischemic stroke patients were significantly older than hemorrhagic stroke patients $(59.9 \pm 14.0$ vs. $47.4 \pm 21.5$ years; $p=0.014$ ). Thus, older age could cause higher vulnerability to depressive mood in ischemic stroke patients than in hemorrhagic stroke patients.

Our study showed that lesion of the right posterior cerebellar hemisphere was a risk factor for depressive mood, which was consistent with the findings of prior research studies [32,33]. The researchers argued that the posterior lobe, not the anterior lobe, contributed to higherlevel processes such as mood regulation [32]. Besides, Damasio et al. [33] demonstrated that the right posterior cerebellar hemisphere was significantly activated by emotions such as anger and fear. A neuroanatomical study has shown that cerebellar hemispheres project to the contralateral dorsolateral prefrontal cortex (DLPFC) through dentatothalamic fiber tracts and receive cortical input back to the cerebellum, forming a closed prefrontal-cerebellar circuit [34]. Imbalance between the left and right DLPFC was demonstrated in major depressive disorder and it was linked to negative emotional judgment [35]. In our study, a lesion in the right posterior cerebellar hemisphere might have affected the balance between the left and right DLPFCs via the prefrontal-cerebellar circuit, causing depressive mood. Although prior studies showed that the cerebellar vermis and paravermian area are the most important anatomical locations in the cerebellum responsible for emotional control [10,36,37], our results showed no statistical correlation between cerebellar vermian lesion and depressive mood. The reason for this might be the small number of patients with a cerebellar vermian lesion alone. Most of the subjects had mixed hemispheric and vermian lesions, or no vermian 
lesion at all. This might have affected the results. Further study is needed to localize the lesion associated with depressive mood in patients with isolated cerebellar stroke by using functional neuroimaging for brain connectivity.

This study has some limitations. First, the subjects' cognitive impairment could have influenced the development of depressive mood, as they were patients who had mild to moderate cognitive impairment. As GDS is a screening tool for subjective depressive mood, reliable data could not be obtained from patients with moderate cognitive impairment. Second, the development of depressive mood could be affected by the other functional factors in subjects such as balance [38] and fatigue [39]. In our study, the subjects' functional status was evaluated only with the FIM score, which does not correlate well with balance function or energy expenditure in stroke patients [40]. Third, the number of subjects was small. Further study with a prospective cohort design, large number of subjects, and considerations of cognitive and other functional factors is needed.

In conclusion, older age, history of hypertension, ischemic stroke, and especially lesion of the right posterior cerebellar hemisphere in patients with cerebellar stroke could confer a higher risk of developing depressive mood. During rehabilitation, the patients with these factors should undergo careful observation of emotional changes for early detection and management of depressive mood in patients with isolated cerebellar stroke.

\section{CONFLICT OF INTEREST}

No potential conflict of interest relevant to this article was reported.

\section{REFERENCES}

1. Hackett ML, Pickles K. Part I: Frequency of depression after stroke: an updated systematic review and meta-analysis of observational studies. Int J Stroke 2014;9:1017-25.

2. Matsuzaki S, Hashimoto M, Yuki S, Koyama A, Hirata Y, Ikeda M. The relationship between post-stroke depression and physical recovery. J Affect Disord 2015;176:56-60.

3. Choi-Kwon S, Han K, Choi S, Suh M, Kim YJ, Song H, et al. Poststroke depression and emotional inconti- nence: factors related to acute and subacute stages. Neurology 2012;78:1130-7.

4. De Ryck A, Fransen E, Brouns R, Geurden M, Peij D, Marien P, et al. Poststroke depression and its multifactorial nature: results from a prospective longitudinal study. J Neurol Sci 2014;347:159-66.

5. Tang WK, Chan SS, Chiu HF, Ungvari GS, Wong KS, Kwok TC, et al. Poststroke depression in Chinese patients: frequency, psychosocial, clinical, and radiological determinants. J Geriatr Psychiatry Neurol 2005; 18:45-51.

6. Flaster M, Sharma A, Rao M. Poststroke depression: a review emphasizing the role of prophylactic treatment and synergy with treatment for motor recovery. Top Stroke Rehabil 2013;20:139-50.

7. Gabaldon L, Fuentes B, Frank-Garcia A, Diez-Tejedor E. Poststroke depression: importance of its detection and treatment. Cerebrovasc Dis 2007;24 Suppl 1:181-8.

8. De Ryck A, Brouns R, Fransen E, Geurden M, Van Gestel G, Wilssens I, et al. A prospective study on the prevalence and risk factors of poststroke depression. Cerebrovasc Dis Extra 2013;3:1-13.

9. De Ryck A, Brouns R, Geurden M, Elseviers M, De Deyn PP, Engelborghs S. Risk factors for poststroke depression: identification of inconsistencies based on a systematic review. J Geriatr Psychiatry Neurol 2014;27:147-58.

10. Strata P. The emotional cerebellum. Cerebellum 2015;14:570-7.

11. O'Halloran CJ, Kinsella GJ, Storey E. The cerebellum and neuropsychological functioning: a critical review. J Clin Exp Neuropsychol 2012;34:35-56.

12. Shah SA, Doraiswamy PM, Husain MM, Escalona PR, $\mathrm{Na}$ C, Figiel GS, et al. Posterior fossa abnormalities in major depression: a controlled magnetic resonance imaging study. Acta Psychiatr Scand 1992;85:474-9.

13. LeroiI, O'Hearn E, Marsh L, Lyketsos CG, Rosenblatt A,Ross CA, et al. Psychopathology in patients with degenerative cerebellar diseases: a comparison to Huntington's disease. Am J Psychiatry 2002;159:1306-14.

14. Frank B, Andrzejewski K, Goricke S, Wondzinski E, Siebler M, Wild B, et al. Humor, laughter, and the cerebellum: insights from patients with acute cerebellar stroke. Cerebellum 2013;12:802-11.

15. Kim H, Na DL. Normative data on the Korean version of the Western Aphasia Battery. J Clin Exp Neuropsy- 
chol 2004;26:1011-20.

16. Linacre JM, Heinemann AW, Wright BD, Granger CV, Hamilton BB. The structure and stability of the Functional Independence Measure. Arch Phys Med Rehabil 1994;75:127-32.

17. Sivrioglu EY, Sivrioglu K, Ertan T, Ertan FS, Cankurtaran E, Aki O, et al. Reliability and validity of the Geriatric Depression Scale in detection of poststroke minor depression. J Clin Exp Neuropsychol 2009;31:9991006.

18. Kim JY, Park JH, Lee JJ, Huh Y, Lee SB, Han SK, et al. Standardization of the Korean version of the geriatric depression scale: reliability, validity, and factor structure. Psychiatry Investig 2008;5:232-8.

19. Brown C, Hasson H, Thyselius V, Almborg AH. Poststroke depression and functional independence: a conundrum. Acta Neurol Scand 2012;126:45-51.

20. Sit JW, Wong TK, Clinton M, Li LS. Associated factors of post-stroke depression among Hong Kong Chinese: a longitudinal study. Psychol Health Med 2007;12:11725.

21. Farner L, Wagle J, Engedal K, Flekkoy KM, Wyller TB, Fure B. Depressive symptoms in stroke patients: a 13 month follow-up study of patients referred to a rehabilitation unit. J Affect Disord 2010;127:211-8.

22. Ayerbe L, Ayis S, Rudd AG, Heuschmann PU, Wolfe CD. Natural history, predictors, and associations of depression 5 years after stroke: the South London Stroke Register. Stroke 2011;42:1907-11.

23. Paolucci S, Gandolfo C, Provinciali L, Torta R, Toso V; DESTRO Study Group. The Italian multicenter observational study on post-stroke depression (DESTRO). J Neurol 2006;253:556-62.

24. Tang WK, Chen YK, Lu JY, Chu WC, Mok VC, Ungvari GS, et al. Cerebral microbleeds and depression in lacunar stroke. Stroke 2011;42:2443-6.

25. Mirowsky J, Ross CE. Age and depression. J Health Soc Behav 1992;33:187-205.

26. Hackett ML, Anderson CS. Predictors of depression after stroke: a systematic review of observational studies. Stroke 2005;36:2296-301.

27. Alexopoulos GS. Depression in the elderly. Lancet 2005;365:1961-70.

28. Yao H, Sadoshima S, Ibayashi S, Kuwabara Y, Ichiya Y, Fujishima M. Leukoaraiosis and dementia in hypertensive patients. Stroke 1992;23:1673-7.
29. Wang L, Leonards CO, Sterzer P, Ebinger M. White matter lesions and depression: a systematic review and meta-analysis. J Psychiatr Res 2014;56:56-64.

30. Meurs M, Groenewold NA, Roest AM, van der Wee NJ, Veltman DJ, van Tol MJ, et al. The associations of depression and hypertension with brain volumes: independent or interactive? Neuroimage Clin 2015;8:7986.

31. van de Port IG, Kwakkel G, Bruin M, Lindeman E. Determinants of depression in chronic stroke: a prospective cohort study. Disabil Rehabil 2007;29:353-8.

32. Stoodley CJ, Schmahmann JD. Functional topography in the human cerebellum: a meta-analysis of neuroimaging studies. Neuroimage 2009;44:489-501.

33. Damasio AR, Grabowski TJ, Bechara A, Damasio H, Ponto LL, Parvizi J, et al. Subcortical and cortical brain activity during the feeling of self-generated emotions. Nat Neurosci 2000;3:1049-56.

34. Middleton FA, Strick PL. Cerebellar projections to the prefrontal cortex of the primate. J Neurosci 2001;21:700-12.

35. Grimm S, Beck J, Schuepbach D, Hell D, Boesiger P, Bermpohl F, et al. Imbalance between left and right dorsolateral prefrontal cortex in major depression is linked to negative emotional judgment: an fMRI study in severe major depressive disorder. Biol Psychiatry 2008;63:369-76.

36. Alalade E, Denny K, Potter G, Steffens D, Wang L. Altered cerebellar-cerebral functional connectivity in geriatric depression. PLoS One 2011;6:e20035.

37. Baldacara L, Nery-Fernandes F, Rocha M, Quarantini LC, Rocha GG, Guimaraes JL, et al. Is cerebellar volume related to bipolar disorder? J Affect Disord 2011;135:305-9.

38. Hama S, Yamashita H, Shigenobu M, Watanabe A, Hiramoto $\mathrm{K}$, Takimoto $\mathrm{Y}$, et al. Sitting balance as an early predictor of functional improvement in association with depressive symptoms in stroke patients. Psychiatry Clin Neurosci 2007;61:543-51.

39. Wu S, Barugh A, Macleod M, Mead G. Psychological associations of poststroke fatigue: a systematic review and meta-analysis. Stroke 2014;45:1778-83.

40. Cunha IT, Lim PA, Henson H, Monga T, Qureshy H, Protas EJ. Performance-based gait tests for acute stroke patients. Am J Phys Med Rehabil 2002;81:84856. 